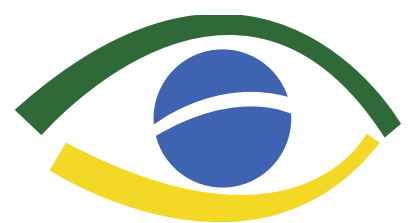

Observatório da Jurisdiçãc Constitucional
Observatório da Jurisdição Constitucional. Ano 6, no. 2, out./2013. ISSN 1982-4564.

\title{
Divulgação da remuneração ou subsídio do agente público na internet: análise da Lei de Acesso à Informação (LAI) à luz dos princípios da publicidade e transparência
}

\author{
Carlos Odon Lopes da Rocha
}

Resumo: Tendo-se em vista a crescente popularização do acesso às informações constantes da Internet, o presente artigo busca demonstrar a constitucionalidade da Lei de Acesso à Informação (Lei n. ${ }^{\circ}$ 12.527/2011), ressaltando que a divulgação da remuneração ou subsídio dos agentes públicos na rede mundial de computadores não põe em risco a segurança pessoal ou familiar do servidor. De igual modo, não se trata de uso indevido do nome do agente público ou de abuso da mídia. Por fim, a disponibilização da remuneração ou subsídio do servidor público ou do agente político não caracteriza ofensa ao direito fundamental à vida privada e à intimidade, por se tratar de informação pública, e não particular. A Lei n. ${ }^{\circ}$ 12.527/2011 visa dar concretude aos princípios republicanos da publicidade, transparência e acesso à informação de dados públicos.

Palavras-chave: Democracia. Remuneração. Subsídio. Divulgação. Internet. Publicidade. Transparência. Segurança. Nome. Mídia. Liberdade. Vida privada. Informação.

\begin{abstract}
Considering the growing popularization of access to information in the Internet, this article seeks to demonstrate the constitutionality of the law on access to information (Law n. ${ }^{\circ}$ 12.527/2011), emphasizing that the disclosure of remuneration or allowance of public workers in the world wide web doesn't endanger the personal safety or family of the worker. Similarly, this isn't a misuse of the name of the public official or abuse of the media. Finally, the provision of remuneration or allowance of public servants or political agent doesn't constitute any violation of the fundamental right to privacy and intimacy, because it is public information, not private. The Law n. ${ }^{\circ}$ 12.527/2011 aims to give concreteness to the republican principles of publicity, transparency and access to information of public data.
\end{abstract}

Keywords: Democracy. Remuneration. Allowance. Disclosure. Internet. Advertising. Transparency. Security. Name. Media. Freedom. Privacy. Information.

\footnotetext{
* Procurador do Distrito Federal. Advogado. Pós-graduado em Direito Público pelo IDP. Pós-graduado em Direito Processual Civil pela Universidade Anhanguera. Mestrando em Direito Constitucional pelo IDP
} 


\section{Introdução}

Com a edição da Lei n. $.^{\circ} 12.527 / 2011$, vulgarmente conhecida como Lei de Acesso à Informação (LAI), houve uma intensa controvérsia no universo jurídico brasileiro no que diz respeito à suposta suplantação do direito fundamental à intimidade, especialmente diante da divulgação, vinculada ao respectivo nome, das remunerações e subsídios de agentes públicos na rede mundial de computadores.

Antes de adentrarmos no debate constitucional envolvendo a matéria, deve ser destacado o contexto normativo em que foi promulgada a citada lei.

O artigo $5^{\circ}$, inciso XXXIII, da Constituição Federal de 1988 reconhece, como direito fundamental do indivíduo, o acesso à informação pública, ao asseverar que

Todos têm direito a receber dos órgãos públicos informações de seu interesse particular, ou de interesse coletivo ou geral, que serão prestadas no prazo da lei, sob pena de responsabilidade, ressalvadas aquelas cujo sigilo seja imprescindível à segurança da sociedade e do Estado.

De igual modo, o artigo 13 da Convenção das Nações Unidas contra a Corrupção, ratificada pelo Decreto n. ${ }^{0}$ 5.687/2006, dispõe que a participação da sociedade na luta contra a corrupção deve ser garantida pelo Estado, com a garantia de acesso eficaz do público à informação. ${ }^{1}$

Portanto, a LAI foi editada com o propósito de conferir efetividade ao direito fundamental de acesso à informação pública, razão pela qual a diretriz interpretativa do hermeneuta deve seguir o seguinte raciocínio: o acesso como regra; o sigilo como exceção.

Já em um quadro comparativo, nunca assaz lembrar que o presente tema não é uma novidade exclusivamente brasileira. Dezenas de países já possuem uma tradição de acesso à informação, principalmente quando se trata de transparência de gastos públicos.

\footnotetext{
${ }^{1}$ Artigo 13. Participação da sociedade.

1. Cada Estado Parte adotará medidas adequadas, no limite de suas responsabilidades e de conformidade com os princípios fundamentais de sua legislação interna, para fomentar a participação ativa de pessoas e grupos que não pertençam ao setor público, como a sociedade civil, as organizações não-governamentais e as organizações com base na comunidade, na prevenção e na luta contra a corrupção, e para sensibilizar a opinião pública a respeito à existência, às causas e à gravidade da corrupção, assim como a ameaça que esta representa. Essa participação deveria esforçar-se com medidas como as seguintes:

a) Aumentar a transparência e promover a contribuição da cidadania aos processos de adoção de decisões;

b) Garantir o acesso eficaz do público à informação;
} 
Com essas breves considerações iniciais, passemos à análise da contemporânea visão de democracia, que servirá de ferramenta para uma adequada interpretação deste hard case.

\section{A contemporânea visão de democracia}

A convivência democrática, como é cediço, consiste na possibilidade de se responsabilizar as autoridades governamentais perante o público. É pressuposto de uma democracia que os atos e ações do Poder Público sejam conhecidos pela coletividade. Ela (a democracia), ao contrário dos regimes autoritários, é o regime do poder visível ou, nas palavras de Bobbio, o "governo do poder público, em público". ${ }^{2}$

Destarte, no Estado intitulado democrático, a coisa pública (res publica) deve ser objeto de controle não somente por órgãos institucionalizados, mas, sobretudo, pela coletividade. De fato, em uma repartição harmônica das funções estatais, cada qual é responsável pela fiscalização de si e do outro, através das instituições competentes (Ministério Público, Tribunal de Contas, Poder Judiciário, Conselhos Nacionais, Corregedorias etc). Porém, o controle institucionalizado, por si só, não é suficiente. É necessário um efetivo controle social a ser exercido pela cidadania, inclusive com a possibilidade de manejo, se for o caso, de ações constitucionais que ataquem eventual corrupção administrativa e mantenham incólume a moralidade e o patrimônio público (p.ex, ação popular).

Nessa concepção da contemporânea filosofia política, portanto, a democracia não é apenas caracterizada por eleições periódicas e o exercício universal do voto secreto, mas pelo "governo por meio do debate" (expressão utilizada originariamente por Walter Bagehot). ${ }^{3}$ Trata-se de uma democracia deliberativa, onde os cidadãos deliberam e trocam opiniões sobre os respectivos argumentos num exercício da razão discursiva (Habermas). ${ }^{4}$ Mas para que isso aconteça, torna-se imprescindível o pleno acesso e a ampla circulação da informação de interesse coletivo, possibilitando, assim, a intensa participação política, a interação pública e o diálogo sincero.

\footnotetext{
${ }^{2}$ BOBBIO, Norberto. O futuro da democracia. $11^{\text {a }}$ ed. São Paulo: Paz e Terra, 2000.

${ }^{3}$ Apud SEN, Amartya. A ideia de justiça. Trad. Denise Bottmann/Ricardo Doninelli Mendes. São Paulo: Companhia das Letras, 2011, p. 358.

${ }^{4}$ HABERMAS, Jurgen. Direito e Democracia: entre facticidade e validade. vol. II. Trad: Flávio Beno Siebeneichler. Rio de Janeiro: Tempo Brasileiro, 2011.
} 
Colocadas tais premissas, veremos a seguir os principais pontos controvertidos a respeito da divulgação na rede mundial de computadores das remunerações e subsídios dos servidores públicos e agentes políticos.

\section{Do suposto risco de exposição da segurança pessoal}

Inicialmente, alguns defendem que a divulgação da remuneração ou subsídio dos agentes públicos vinculada ao respectivo nome acarreta um risco de exposição da segurança pessoal e familiar ${ }^{5}$.

Contudo, este argumento não convence.

De fato, a divulgação nominal das remunerações/subsídios faz com que a segurança pessoal e familiar do agente público fique um tanto mais fragilizada. Porém, fica fragilizada a segurança tanto quanto qualquer outro sinal de ostentação exterior de riqueza por parte de tais agentes. A partir do insustentável peso dos exemplos, a divulgação nominal da remuneração do servidor público expõe a sua segurança tanto quanto a aquisição de um novo veículo automotor.

Em suma, a fragilização da segurança do agente público é um argumento falacioso,

porque hoje, para diversos fins - inclusive para fins familiares e outros aspectos que interessam aos juízos penais -, a riqueza aparente também tem muita influência e as pessoas que ganham esses salários levam uma vida compatível com esses salários, que revelam a riqueza aparente. (STF. SS 3.902/SP - AgR. Trecho do voto do Ministro Luiz Fux).

Além do mais, o intérprete/aplicador do direito, trilhando o caminho kantiano, não pode valorar moralmente uma ação a partir de suas consequências, mas na intenção com a qual a ação é realizada. O que importa é fazer a coisa certa porque é a coisa certa, e não por algum outro motivo exterior a ela.

\footnotetext{
${ }^{5}$ Em entrevista dada por André Ramos Tavares ao Jornal Carta Forense (edição de setembro de 2012), afirma o constitucionalista que "não há necessidade e nem adequação de medida tão extrema, pois é possível - por inúmeras maneiras - agir com ampla transparência sem subtrair a privacidade de seus servidores, nem colocálos em risco de segurança" (Apud PÉRES, Taynah Litaiff Isper Abrahim Carpinteiro. A lei de acesso à informação e a divulgação nominal da remuneração dos servidores públicos. Da transmutação do 'interesse público' em 'curiosidade coletiva'. Jus Navigandi, Teresina, ano 17, n. 3402, 24 out. 2012, Disponível em: <http://jus.com.br/artigos/22867>. Acesso em 08 ago. 2013.
} 
Por exemplo, temos que, atualmente, nas grandes metrópoles brasileiras, parar o veículo no semáforo a partir das $22 \mathrm{hs} 00$ min expõe o motorista a um risco em sua segurança pessoal. Mas nem por isso é lícito ou permitido a ele desrespeitar o semáforo vermelho. Apreciar a moralidade da conduta ou um argumento de princípio a partir de uma visão consequencialista ou utilitarista (Stuart Mill e Bentham) seria inviável numa sociedade civilizada, como nos ensina Ronald Dworkin. ${ }^{6}$

Em outras palavras, o risco à segurança pessoal e familiar do agente público, com a divulgação nominal de sua remuneração/subsídio, deve ser sério, claro, concreto e iminente, e não apenas formulado de maneira genérica e abstrata.

Certa vez disse o Justice Brennan, da Suprema Corte americana, que

(...) basta que se pegue qualquer jornal ou revista para compreender a vasta gama de material publicado que expõe pessoas à observação pública, tanto cidadãos privados como ocupantes de cargos públicos. A exposição de si a outros em graus variados é concomitante à vida em uma comunidade civilizada. O risco dessa exposição é um incidente essencial da vida em uma sociedade que atribui um valor primordial à liberdade de expressão e de imprensa" (Time, Inc. vs Hill. 1967). ${ }^{7}$

\section{Da suposta ofensa ao uso indevido do nome do agente público}

Sob outra vertente, há quem diga que o nome é um direito de personalidade do indivíduo, motivo pelo qual possui natureza inviolável e, por isso, pode ser objeto de tutela judicial, com o escopo de adotar as providências necessárias para impedir ou fazer cessar ato contrário a esta norma.

Conquanto correto, o argumento acima resta incompleto. Para uma melhor compreensão, faz-se mister um prévio e sucinto estudo sobre o instituto jurídico em questão ("nome").

O nome é um dos atributos da pessoa, que o usa como signo distintivo ${ }^{8}$. Todavia, além de configurar um elemento da personalidade, é também um dever, "dever que se tem de ser identificado socialmente (...). Aqui, o que se leva em consideração é a sua função

\footnotetext{
${ }^{6}$ DWORKIN, Ronald. Levando os direitos a sério. Trad. Nelson Boeira. $3^{\mathrm{a}}$ ed. São Paulo: Martins Fontes, 2010.

7 Apud LEWIS, Anthony. Liberdade para as ideias que odiamos: uma biografia da primeira emenda à Constituição americana. Trad. Rosana Nucci. São Paulo: Aracati, 2011, p. 87.

${ }^{8}$ TEPEDINO, Gustavo; BARBOZA, Heloísa H; MORAES, Maria Celina Bodin de. In: Código Civil interpretado conforme a Constituição da República. Vol. 1. Rio de Janeiro: Renovar, 2004, p. 44
} 
identificadora do indivíduo, não mais em relação a si mesmo, à sua personalidade e dignidade, mas em relação à comunidade em que se encontra inserido e ao Estado", consoante ensina Maria Celina Bodin de Moraes ${ }^{9}$. Por descuido ou má-fé, muitos doutrinadores olvidam dessa outra face atinente ao nome.

Nesse mesmo norte, ensinava Serpa Lopes, já no início do século XX, que o nome é um "misto de direito e obrigação", pois, não obstante representar relevante atributo da personalidade, há um interesse social e coletivo na sua existência e nos seus elementos integrantes. ${ }^{10}$ Com efeito, as relações jurídicas se estabelecem entre pessoas naturais e jurídicas, cujo exercício dos respectivos direitos exige que se conheça quem são os titulares. E só se conhece os titulares através dos respectivos nomes, e não de matrículas funcionais, cadastros de pessoas físicas (CPFs) ou registros gerais (RGs). É com o nome que a identificação da pessoa torna-se possível, o que permite um controle social efetivo, como, por exemplo, a averiguação de nepotismo e a acumulação ilícita de cargos.

Oportuno mencionar, ainda, que o artigo 17 do Código Civil brasileiro dispõe que " $O$ nome da pessoa não pode ser empregado por outrem em publicações ou representações que a exponham ao desprezo público, ainda quando não haja intenção difamatória".

Depreende-se de uma leitura atenta de tal dispositivo legal que a pessoa pode defender o seu nome contra qualquer agressão ou exposição ao desprezo público, com o fito de evitar que o nome se torne ridículo, odioso ou desprezível.

Entretanto, seguindo os passos de Maria Celina Bodin de Moraes, o nome não é protegido em si e per si. O nome de alguém só não pode ser utilizado por outrem (particular ou Estado) quando puder ensejar desprezo público ou escárnio, nos termos do art. 17 do Código Civil. Tanto isso é verdade que o emprego do nome com o intuito de gerar simpatia na opinião pública não é objeto de tutela preventiva, inibitória ou reparatória. Dessa forma, o que o ordenamento jurídico pátrio resguarda não é propriamente o nome, mas a pessoa e sua dignidade, que podem ser, através do nome, atingidas. ${ }^{11}$

Não se vislumbra, pois, qualquer desprezo público ou vexame na divulgação de listagem nominal com as remunerações ou subsídios dos agentes públicos. Não há motivo de

\footnotetext{
${ }^{9}$ MORAES, Maria Celina Bodin de. A tutela do nome da pessoa humana. In: Revista Forense. Rio de Janeiro v. 98, n. 364, nov/dez 2002, p. 220.

${ }^{10}$ Apud TEPEDINO, Gustavo; BARBOZA, Heloísa H; MORAES, Maria Celina Bodin de. Op. cit, p. 44

${ }^{11}$ MORAES, Maria Celina Bodin de. Op. cit, p. 220.
} 
o agente se sentir achincalhado ou humilhado por receber verbas previstas expressamente em lei. São verbas legais e, aprioristicamente, legítimas, sejam elas pagas em caráter permanente ou a título eventual.

Situação vexatória ou desprezível somente se configuraria na hipótese de percepção ilícita de vantagens pecuniárias por parte de agentes públicos, sendo vítima, nessa circunstância, a coletividade - e não o servidor ou agente político. Cabe, destarte, a qualquer cidadão, em defesa da moralidade administrativa e do patrimônio público, ajuizar a competente ação popular, verdadeiro direito fundamental de participação da cidadania na esfera pública (art. 5º LXXIII, da Constituição Federal de 1988).

Como dito pelo Ministro Gilmar Mendes, “(...) acho que é isto que se quer fazer: um tipo de controle social mostrando que às vezes há uma evolução salarial não ortodoxa a partir de deferimento de pedidos, acréscimos, ações judiciais" (STF. SS 3.902/SP). E complementando tal entendimento, disse o Ministro Marco Aurélio, no mesmo julgamento, que “(...) há o risco, como sempre salientou o Ministro Marcelo Pimentel, de ter-se os penduricalhos escamoteados".

Com isso, ao abrir a possibilidade de um maior controle social ou popular, fortalecese a democracia, a transparência e, consequentemente, busca-se combater eventual corrupção ainda existente no Poder Público.

\section{Do suposto abuso, pela mídia, das informações obtidas a partir do advento da LAI}

Há, ainda, aqueles que argumentam que o livre acesso às informações somente irá saciar a curiosidade da mídia, que poderá saber quanto ganha determinado agente público, nada trazendo de contribuição efetiva. A mídia irá, portanto, apenas desnudar o servidor público ou agente político.

Segundo essa visão, o acesso da mídia a tais informações não atenderá aos fins da lei, saciando apenas a curiosidade da sociedade acerca de quanto recebe um agente dos cofres públicos.

Data vênia, a referida compreensão não merece ser acolhida, já que as liberdades de expressão e de imprensa consistem, em última análise, na possibilidade de informar as 
pessoas. Somente uma imprensa livre, que não seja controlada, pode expor de forma eficaz eventual fraude no Poder Público.

A relevância que a imprensa livre e independente representa para uma sociedade democrática é inigualável. Uma mídia livre contribui de diversas maneiras para a promoção da justiça, dentre as quais se pode ressaltar o seu papel informativo e investigativo, que difunde o conhecimento e possibilita a análise crítica dos fatos expostos. Disso resultam as críticas da opinião pública e, por conseguinte, o aperfeiçoamento das nossas instituições oficiais. $^{12}$

Em outras palavras, não há de falar em mera curiosidade da mídia, mas, ao contrário, do seu papel ímpar de informar fatos e formar valores, onde novas prioridades emergem da interação discursiva pública e racional.

Ensina Amartya Sen que

(...) uma mídia em bom funcionamento pode ter um papel extremamente importante no sentido de facilitar a argumentação pública em geral (...). Não é difícil ver por que uma mídia livre, enérgica e eficaz pode facilitar o necessário processo do debate. A mídia é importante não só para a democracia, mas para a busca da justiça em geral. Uma "justiça sem debate" pode revelar-se uma ideia opressiva. ${ }^{13}$

Ainda que se admita que a mídia tenha os interesses e desejos mais baixos e inconfessáveis no que tange à divulgação da lista nominal das remunerações e subsídios dos servidores públicos e agentes políticos, mesmo assim nada pode afastar, a priori, a liberdade de imprensa, sob pena de se instituir a famigerada figura do censor: um árbitro que afere a qualidade da informação, dando o aval ou não para a sua divulgação.

Obviamente, nenhum direito é absoluto, assim como a liberdade (de imprensa) não pode servir para salvaguardar condutas ilícitas. Nesse sentido, a liberdade de imprensa há de ter como limite intrínseco a informação verdadeira ou, ao menos, a informação divulgada com o propósito de narrar sinceramente a verdade. A falsidade deliberada e intencional na informação não está protegida pela liberdade de expressão ou de imprensa. A comunicação social não pode - e não deve - aceitar a distorção dolosa da verdade. ${ }^{14}$ Causando dano, a imprensa deverá reparar. Havendo perigo real e concreto de dano, a imprensa será inibida,

\footnotetext{
${ }^{12}$ SEN, Amartya. Op. cit. p. 370.

${ }^{13}$ Idem. p. 371.

${ }^{14}$ Cf. MENDES, Gilmar Ferreira; COELHO, Inocêncio Mártires; BRANCO, Paulo Gustavo Gonet. Curso de Direito Constitucional. São Paulo: Saraiva, 2007, p. 361/363.
} 
sempre mediante tutela judicial célere e adequada. Porém, nunca demais repetir, o simples medo de dano abstrato não justifica eventual repressão à imprensa.

Nos dizeres de Paulo José da Costa Júnior,

(...) para se exercitar o direito de crônica, que está intimamente conexo com o de receber informações, será mister que se atenda ao interesse da coletividade de ser informada, porque através dessas informações é que se forma a opinião pública, e será necessário que a narrativa retrate a verdade(...). O erro pode ser tolerado, mas desde que "o jornalista se tenha valido de uma fonte de informação válida e reconhecida, caso não tenha tido conhecimento direto do fato. ${ }^{15}$

De fato, a imprensa, através de tumultos verbais, não raras vezes difama determinada pessoa, seja ela pública ou privada, causando-lhe danos à sua reputação e dignidade. E, uma vez ocorrendo tal situação de ilegalidade, será franqueada à parte prejudicada a tutela reparatória e, em alguns casos, as tutelas preventiva e inibitória.

Como já disse o Justice Harlan, da Suprema Corte americana, "que o ar pode, às vezes, parecer cheio de cacofonias verbais é, nesse sentido, não um sinal de fraqueza, mas de força (da liberdade de expressão e de imprensa)". ${ }^{16}$

Resumindo, não cabe ao intérprete agir como censor ou árbitro do bom gosto. Conquanto seja de todo conveniente uma abordagem imparcial e prudente, o fato de a mídia adotar uma análise eventualmente mais sensacionalista não pode ser objeto de uma prévia repressão jurídica. A despeito da probabilidade de ocorrência de abusos, a liberdade de imprensa é, a longo prazo, essencial para a formação de uma opinião pública mais esclarecida e para uma conduta reta das autoridades públicas.

\section{Da suposta ofensa à vida privada do agente público com a divulgação nominal das remunerações e subsídios}

Sob um último aspecto, resta saber se a divulgação da remuneração ou subsídio dos

\footnotetext{
${ }^{15}$ COSTA JÚNIOR, Paulo José. O direito de estar só. São Paulo: RT, 1995, p. 67/68. No mesmo sentido é a lição de Edilson Farias: “(...) no Estado democrático de direito o que se espera do sujeito emissor de uma notícia, como postura que denota apreço pela verdade, é o diligente contato com as fontes das informações, examinando-as e confrontando-as, bem como o uso de todos os meios disponíveis ao seu alcance, como medidas profiláticas, para certificar-se da idoneidade do fato antes de sua veiculação” (FARIAS, Edilson. Liberdade de expressão e comunicação. São Paulo: RT, 2004, p. 91)

${ }^{16}$ Apud LEWIS, Anthony. Op. cit, p. 158.
} 
servidores públicos e agentes políticos, com vinculação direta aos seus nomes, acarreta ofensa ao direito fundamental individual previsto no art. $5^{\circ}$, inciso $\mathrm{X}$, da $\mathrm{CF} / 88$ ("São invioláveis a intimidade, a vida privada, a honra e a imagem das pessoas, assegurado o direito à indenização pelo dano material ou moral decorrente de sua violação").

Esta é, sem dúvida, a questão mais tormentosa e complexa. Os limites aos princípios da publicidade, da transparência nos gastos públicos e do amplo acesso à informação, acaso existentes, serão estabelecidos pelo direito à privacidade do ser humano.

Porém, após o desenvolvimento teórico a seguir, ficará demonstrada a inexistência de conflito ou tensão entre os referidos princípios.

O direito à privacidade é conceituado mundo afora, desde 15 de dezembro de 1890 , com a publicação do artigo "The right to privacy" na Harvard Law Review, vo. IV, de Samuel D. Warren e L. D. Brandeis, como sendo o direito de o indivíduo estar só (right to be let alone $)^{17}$. É o direito de o ser humano permanecer isolado e solitário, com seus próprios infernos e paraísos particulares. Caracteriza-se pelo direito de ser deixado em paz, de viver a própria vida como escolher, livre de agressão ou invasão por parte de terceiros.

Nesse sentido, é indiscutível a necessidade de proteção da vida privada do agente público. Não se admite - e a lei segue tal norte - que dados exclusivamente particulares constantes dos contracheques sejam divulgados ampla e irrestritamente. Não se cogita, por exemplo, sob pena de inconstitucionalidade por ofensa à privacidade, de divulgação de dados referentes a pensões alimentícias, empréstimos consignados, descontos para planos de saúde, associações esportivas, seguros, sindicatos etc. Essas são informações do agente público não enquanto agente público, mas enquanto alimentante, contratante particular, associado, sindicalizado etc. Em suma, não são informações públicas, mas pessoais e particulares.

Entretanto, ao agente público enquanto agente público, já teve oportunidade de consignar o Ministro Carlos Ayres Britto (SS 3902/SP), deve incidir os princípios da publicidade e da informação, além do dever de prestar contas. Todos têm o direito inalienável de saber e controlar, específica e detalhadamente, os atos que são praticados pelo Poder Público, inclusive aqueles relativos a despesas com pessoal.

\footnotetext{
${ }^{17}$ PERLINGIERI, Pietro. O Direito Civil na Legalidade Constitucional. Rio de Janeiro: Renovar, 2008 , p. 853.
} 
Na vida pública, a transparência deve ser irrestrita e robusta, o que certamente ensejará críticas - muitas vezes demagógicas - a servidores e ao governo em si. Mas esse é o preço que se deve pagar por viver em uma democracia.

O que não pode ser aceito, jamais, é a intromissão na vida íntima ou privada do agente público. Com base nela, o indivíduo possui o direito sagrado de esconder determinados fatos ou somente mostra-los a quem desejar.

Em outras palavras, em uma sociedade democrática, a informação pública - e não pessoal - representa o fundamento de participação do cidadão na vida do país e, portanto, do correto funcionamento das instituições. ${ }^{18}$ Do mesmo modo, a publicidade tem por escopo manter a total transparência na prática dos atos da Administração Pública, que não poderá ocultar ou obstar ao administrado/cidadão o conhecimento de assuntos que o interessem direta ou indiretamente. ${ }^{19}$

Sendo assim, a mera divulgação de informações públicas, como, por exemplo, a remuneração legal de servidor público, não configura ato ilícito, ou seja, não é apto a ensejar dano moral. A $3^{\text {a }}$ Turma Recursal dos Juizados Especiais do Distrito Federal já teve a oportunidade de decidir que, a princípio, a mera divulgação da remuneração do servidor público, quando atrelada ao propósito de controle dos atos públicos, não viola a privacidade e a intimidade da pessoa ${ }^{20}$.

\footnotetext{
${ }^{18}$ Idem, p. 855

${ }^{19}$ BULOS, Uadi Lammego. Curso de Direito Constitucional. São Paulo: Saraiva, 2008, p. 806

${ }^{20}$ DIREITO CIVIL. RESPONSABILIDADE CIVIL. DIVULGAÇÃO DE NOME E REMUNERAÇÃO DE SERVIDOR PÚBLICO. DIREITO À INTIMIDADE E PRIVACIDADE. LIMITE REMUNERATTÓRIO. DIREITO À INFORMAÇÃO. LIBERDADE DE IMPRENSA. PRINCÍPIO DA PUBLICIDADE DA ADMINISTRAÇÃO PÚBLICA. PRINCÍPIO HERMENÊUTICO CONSTITUCIONAL DA CONCORDÂNCIA PRÁTICA OU HARMONIZAÇÃO. CONTROLE DOS ATOS DA ADMINISTRAÇÃO PÚBLICA. PROPÓSITO INFORMATIVO. DANO MORAL NÃO CONFIGURADO. NEGADO PROVIMENTO AO RECURSO. SENTENÇA MANTIDA.

$\mathrm{O}$ autor, agente público, narra que o réu divulgou indevidamente na internet seus dados pessoais e informações sigilosas, tais como nome e remuneração, o que lhe causou transtornos e aborrecimentos. Considera que a divulgação dessas informações expuseram-no a situações indesejáveis, constrangedoras e de risco, bem como violaram sua intimidade e vida privada. Pretende reparação por danos morais no valor de $\mathrm{R} \$ 21.800,00$ (vinte e um mil e oitocentos reais).

O réu sustenta a legalidade da divulgação da remuneração dos servidores públicos e que entendimento contrário consistiria em tentativa de inviabilizar a prática da atividade jornalística. Defende a liberdade de imprensa e o direito à informação. Deduz pedido contraposto.

O d. Juízo de Primeiro Grau julgou improcedentes os pedidos do autor e do réu.

$\mathrm{O}$ recorrente sustenta a abusividade das informações divulgadas pelo recorrido, com a indicação do seu nome completo, remuneração e local de trabalho, extrapolando o direito de informar. Alega violação a sua honra e intimidade.
} 
Portanto, a indicação nominal de remuneração de servidor público ou de subsídio de agente político não caracteriza informação pessoal, mas, ao contrário, informação pública.

Calha ressaltar que, desde há muito, os aprovados em certames públicos são listados nominalmente pela Administração, com ampla divulgação nos mais diversos meios de comunicação, sendo certo que as remunerações dos seus cargos estão expressamente previstos em lei e no edital. Nem por isso alega-se, quando o candidato é aprovado no concurso público, ofensa à sua vida privada ou à sua intimidade. Sendo admissível a divulgação do nome do agente público vinculado à remuneração bruta do cargo, não se vislumbra qualquer fator de discriminação lógico-racional a justificar um tratamento diferenciado em relação a outras vantagens pecuniárias atinentes ao mesmo cargo público para o qual foi aprovado, sejam elas percebidas a título permanente ou eventual.

O recorrido alega ter havido inovação em sede recursal e a mitigação dos direitos à intimidade e à vida privada. Defende a liberdade de informação jornalística e o direito à informação, bem como a inaplicabilidade dos julgados transcritos no recurso.

Não assiste razão ao recorrente.

Não se trata de negar os direitos à intimidade ou vida privada do recorrente, porém, de se definir, no caso concreto, quais os limites do exercício desses direitos. Nenhum direito será exercido de forma absoluta. Além dos direitos à intimidade e à vida privada, a Constituição Federal garante os direitos à liberdade de imprensa e ao acesso à informação, assim como o respeito ao princípio da publicidade da Administração Pública, sendo necessário valermo-nos do princípio hermenêutico constitucional da concordância prática ou harmonização para compatibilizá-los no caso concreto.

O art. 5, X, da Constituição Federal de 1988 garante a inviolabilidade da intimidade e vida privada. Por sua vez, o art. $5^{\circ}$, XXXIII, dispõe que todos têm direito a receber dos órgãos públicos informações de seu interesse particular, ou de interesse coletivo ou geral, que serão prestadas no prazo da lei, sob pena de responsabilidade, ressalvadas aquelas cujo sigilo seja imprescindível à segurança da sociedade e do Estado.

$\mathrm{O}$ art. 37, § $3^{\circ}$, II, da Constituição Federal de 1988 também garante o acesso dos usuários a registros administrativos e a informações sobre atos de governo, observado o disposto no art. $5^{\circ}$, X e XXXIII.

$\mathrm{O}$ art. 5 XIV, da Constituição Federal de 1988 assegura a todos o acesso à informação.

$\mathrm{O}$ art. 37, caput, da Constituição Federal de 1988 estabelece a publicidade como princípio básico da Administração Pública.

O art. 37, XI, da Constituição Federal de 1988 fixa limites para a remuneração dos servidores públicos.

Com o objetivo de conferir maior transparência à Administração Pública, a Lei nº 12.527/2011 regula, no âmbito infraconstitucional, como será exercido o direito ao acesso à informação.

Percebe-se que é inerente ao Estado Democrático de Direito o controle dos atos governamentais realizado pelo próprio cidadão, razão pela qual há interesse público na divulgação de informações sobre os gastos públicos, remuneração dos seus servidores e o respeito ao teto remuneratório constitucional.

A princípio, a mera divulgação da remuneração do servidor público, quando atrelada ao propósito de controle dos atos públicos, não viola a privacidade e a intimidade da pessoa, como no caso dos autos.

Ante o exposto, NEGO PROVIMENTO ao recurso e mantenho a r. sentença recorrida. Vencida a parte recorrente, deverá arcar com custas processuais e honorários advocatícios, os quais fixo em R \$ 300,00 (trezentos reais), nos termos do art. 20, $\S 4^{\circ}$, do Código de Processo Civil, a teor do art. 55 da Lei n. 9.099, de 26 de setembro de 1995.

Acórdão lavrado conforme o art. 46 da Lei n ${ }^{\circ}$ 9.099, de 26 de setembro de 1995. (ACJ 2011.01.1.200746-6. Rel. Juiz Hector Valverde Santana. $3^{\text {a }}$ Turma Recursal dos Juizados Especiais do Distrito Federal. Julgado em 12 de junho de 2012. DJ de 14.06.2012). 
Além disso, a simples divulgação mediante a inscrição do número de matrícula funcional ou outra forma diversa da nominal dificultaria o controle social ou popular. Assim, a regra hermenêutica é no sentido do acesso pleno, imediato e gratuito às informações públicas, divulgando-as na rede mundial de computadores. A restrição à publicidade somente será justificável na excepcional hipótese de as informações serem confidenciais e sigilosas, além daqueles exclusivamente pessoais.

Qualquer vantagem pecuniária cujo fundamento jurídico seja o exercício do cargo público não configura, a meu ver, informação pessoal, mas, ao revés, informação pública. E não sendo informação de caráter pessoal ou estando classificado como informação sigilosa, o interesse no seu acesso é público, inclusive no que tange à possibilidade de ser acessado por todos.

A acessibilidade, ademais, deve ser facilitada pela Administração Pública. Na sua contemporânea concepção, a conduta do ente estatal em matéria de transparência deve ser ativa, vale dizer, o acesso prévio à informação através da rede mundial de computadores faz com que o cidadão não necessite acionar o órgão, gerando facilidades para ele e economia de tempo e recursos materiais e humanos para a Administração. Cumpre-se, pois, não apenas o princípio da publicidade, mas também o da eficiência.

Apesar de acalorados debates jurisprudenciais, o Supremo Tribunal Federal já acenou, acertadamente, para a licitude da divulgação das remunerações ou subsídios dos servidores públicos e agentes políticos, no âmbito da rede mundial de computadores, consagrando, destarte, o princípio da publicidade a que deve se ater todo administrador público e a efetiva participação da cidadania no controle popular dos atos administrativos.

O Supremo Tribunal Federal, nos autos do Agravo Regimental na Suspensão de Segurança n. ${ }^{\circ}$ 3902/SP, decidiu que a cidadania tem o direito de ver o seu Estado republicanamente administrado. ${ }^{21}$

${ }^{21}$ SUSPENSÃO DE SEGURANÇA. ACÓRDÃOS QUE IMPEDIAM A DIVULGAÇÃO, EM SÍTIO ELETRÔNICO OFICIAL, DE INFORMAÇÕES FUNCIONAIS DE SERVIDORES PÚBLICOS, INCLUSIVE A RESPECTIVA REMUNERAÇÃO. DEFERIMENTO DA MEDIDA DE SUSPENSÃO PELO PRESIDENTE DO STF. AGRAVO REGIMENTAL. CONFLITO APARENTE DE NORMAS CONSTITUCIONAIS. DIREITO À INFORMAÇÃO DE ATOS ESTATAIS, NELES EMBUTIDA A FOLHA DE PAGAMENTO DE ÓRGÃOS E ENTIDADES PÚBLICAS. PRINCÍPIO DA PUBLICIDADE ADMINISTRATIVA. NÃO RECONHECIMENTO DE VIOLAÇÃO À PRIVACIDADE, INTIMIDADE E SEGURANÇA DE SERVIDOR PÚBLICO. AGRAVOS DESPROVIDOS. 
Já sob a égide da Lei n. ${ }^{\circ}$ 12.527/2011, o então Ministro Presidente do STF Carlos

Ayres Britto, em decisão monocrática, reiterou a decisão acima transcrita, aduzindo que:

(...) Ora, no caso dos autos, é evidente estar-se diante de matéria constitucional, devido a que as decisões impugnadas versam o tema do direito fundamental de acesso à informação pública (inciso XXXIII do art. $5^{\circ}$, inciso II do $\S 3^{\circ}$ do art. 37 e $\S 2^{\circ}$ do art. 216 , todos da Constituição Federal), de parelha com o princípio igualmente constitucional da publicidade da atuação administrativa (caput do art. 37 da CF). Princípio que, para além da simples publicidade do agir de toda a Administração Pública, propicia o controle da atividade estatal até mesmo pelos cidadãos. Donde a facilitada conclusão de que decisões judiciais contrárias a tais normais constitucionais de proa gera grave lesão à ordem pública.

Como ainda se faz de facilitada percepção, a remuneração dos agentes públicos constitui informação de interesse coletivo ou geral, nos exatos termos da primeira parte do inciso XXXIII do art. $5^{\circ}$ da Constituição Federal. (SL 623/DF. Julgado em 10 de julho de 2012).

Apenas uma ressalva deve ser dita. A Administração deve divulgar a remuneração ou subsídio dos agentes públicos não somente na sua condição bruta, mas também na condição líquida, após os descontos legais incidentes em folha de pagamento (imposto de renda, contribuição previdenciária etc). Como já visto, eventuais descontos contratuais pertencem à esfera da privacidade do agente público, não podendo, por isso, ser objeto de publicidade.

A divulgação da remuneração ou subsídio após os descontos legais serve para retratar fielmente a realidade dos fatos, evitando que se deixe transparecer no agente público

1. Caso em que a situação específica dos servidores públicos é regida pela $1^{\mathrm{a}}$ parte do inciso $\underline{\mathrm{XXXIII}}$ do art. $\underline{5^{\circ}}$ da Constituição. Sua remuneração bruta, cargos e funções por eles titularizados, órgãos de sua formal lotação, tudo é constitutivo de informação de interesse coletivo ou geral. Expondo-se, portanto, a divulgação oficial. Sem que a intimidade deles, vida privada e segurança pessoal e familiar se encaixem nas exceções de que trata a parte derradeira do mesmo dispositivo constitucional (inciso XXXIII do art. $5^{\circ}$ ), pois o fato é que não estão em jogo nem a segurança do Estado nem do conjunto da sociedade.

2. Não cabe, no caso, falar de intimidade ou de vida privada, pois os dados objeto da divulgação em causa dizem respeito a agentes públicos enquanto agentes públicos mesmos; ou, na linguagem da própria Constituição, agentes estatais agindo "nessa qualidade" ( $\$ 6^{\circ}$ do art. 37). E quanto à segurança física ou corporal dos servidores, seja pessoal, seja familiarmente, claro que ela resultará um tanto ou quanto fragilizada com a divulgação nominalizada dos dados em debate, mas é um tipo de risco pessoal e familiar que se atenua com a proibição de se revelar o endereço residencial, o CPF e a CI de cada servidor. No mais, é o preço que se paga pela opção por uma carreira pública no seio de um Estado republicano.

3. A prevalência do princípio da publicidade administrativa outra coisa não é senão um dos mais altaneiros modos de concretizar a República enquanto forma de governo. Se, por um lado, há um necessário modo republicano de administrar o Estado brasileiro, de outra parte é a cidadania mesma que tem o direito de ver o seu Estado republicanamente administrado. O "como" se administra a coisa pública a preponderar sobre o "quem" administra -falaria Norberto Bobbio -, e o fato é que esse modo público de gerir a máquina estatal é elemento conceitual da nossa República. O olho e a pálpebra da nossa fisionomia constitucional republicana.

4. A negativa de prevalência do princípio da publicidade administrativa implicaria, no caso, inadmissível situação de grave lesão à ordem pública.

5. Agravos Regimentais desprovidos. (SS 3902/SP. Rel. Min. Ayres Britto. Tribunal Pleno. Julgado em 09.06.2011. Publicado em 03.10.2011). 
uma "realidade distorcida", isto é, uma remuneração ou subsídio não condizente com aquela efetivamente percebida. Ao lado da publicidade, transparência e do acesso à informação, todo intérprete do Direito deve ter em mente os princípios deontológicos da lealdade, boa-fé e respeito à verdade substancial dos fatos, a ser aplicados mediante tratamento de dados públicos segundo a licitude e a retidão. Como ensina Egon Bokmann Moreira,

(...) a finalidade do princípio da publicidade é levar a informação definida e precisa, ao conhecimento das pessoas interessadas (potencialmente ou em concreto). O princípio não será atendido caso haja divulgação restrita (seja no que diz respeito ao conteúdo da informação, seja no que diz respeito ao número de pessoas alcançadas). ${ }^{22}$

Destarte, em respeito à lealdade e boa-fé, cabe ao Estado promover a exposição exata das informações.

Em síntese, a divulgação nominal das remunerações ou subsídios de servidores públicos e agentes políticos não afeta ilegitimamente a vida íntima e a esfera privada dos mesmos, existindo, em verdade, uma supremacia do interesse público representada pela transparência dos gastos estatais com a folha de pagamento. Com isso, permite-se um efetivo controle social, com vistas a combater eventuais hipóteses de corrupção no país.

Por fim, sobre a divulgação da remuneração dos servidores públicos vinculada ao respectivo nome, o Supremo Tribunal Federal, igualmente após a edição da Lei n. ${ }^{\circ}$ 12.527/2011, decidiu “divulgar, de forma ativa e irrestrita, os subsídios dos ministros e a remuneração dos servidores do quadro de pessoal do Supremo Tribunal Federal, assim como os proventos dos ministros aposentados, dos servidores inativos e dos pensionistas", o que se deu na 4 ${ }^{\text {a }}$ Sessão Administrativa, realizada em 22 de maio de 2012, por unanimidade (SL 623/DF. Rel. Min. Ayres Britto).

\section{Conclusão}

Portanto, é certo que a divulgação do subsídio e da remuneração, respectivamente, do agente político e do servidor público não atenta contra o princípio fundamental da intimidade e da vida privada. Ao revés, busca a LAI dar concretude aos princípios constitucionais da vida

\footnotetext{
${ }^{22}$ MOREIRA, Egon Bokmann. Processo Administrativo: Princípios Constitucionais e a Lei n. $^{\circ}$ 9.784/99. $2^{\mathrm{a}}$ ed. São Paulo: Malheiros, 2003, p. 125
} 
republicana, quais sejam, o da publicidade e transparência, o que permite à cidadania um maior e mais efetivo controle social sobre as contas e gastos públicos. Além do mais, permite ao cidadão obter informações a respeito de corrupção eventualmente existente na esfera pública, ocasião em que poderá fazer uso da competente ação popular.

Em suma, a correta e completa informação a ser dada pela Administração possibilita uma efetiva autonomia social e política por parte do cidadão, o qual terá mais consciência acerca do fato de não ser apenas o destinatário, mas também o agente legitimador da res publica.

\section{Referências}

BOBBIO, Norberto. O futuro da democracia. $11^{\text {a }}$ ed. São Paulo: Paz e Terra, 2000

BULOS, Uadi Lammego. Curso de Direito Constitucional. São Paulo: Saraiva, 2008

COSTA JÚNIOR, Paulo José. O direito de estar só. São Paulo: RT, 1995

DWORKIN, Ronald. Levando os direitos a sério. Trad. Nelson Boeira. $3^{\mathrm{a}}$ ed. São Paulo: Martins Fontes, 2010

FARIAS, Edilson. Liberdade de expressão e comunicação. São Paulo: RT, 2004

HABERMAS, Jurgen. Direito e Democracia: entre facticidade e validade. vol. II. Trad: Flávio Beno Siebeneichler. Rio de Janeiro: Tempo Brasileiro, 2011

SEN, Amartya. A ideia de justiça. Trad. Denise Bottmann/Ricardo Doninelli Mendes. São Paulo: Companhia das Letras, 2011

LEWIS, Anthony. Liberdade para as ideias que odiamos: uma biografia da primeira emenda à Constituição americana. Trad. Rosana Nucci. São Paulo: Aracati, 2011

MENDES, Gilmar Ferreira; COELHO, Inocêncio Mártires; BRANCO, Paulo Gustavo Gonet. Curso de Direito Constitucional. São Paulo: Saraiva, 2007.

MORAES, Maria Celina Bodin de. A tutela do nome da pessoa humana. In: Revista Forense. Rio de Janeiro v. 98, n. 364, nov/dez 2002.

MOREIRA, Egon Bokmann. Processo Administrativo: Princípios Constitucionais e a Lei $n .^{o}$

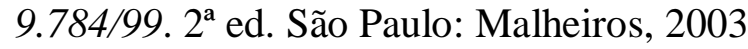

PÉRES, Taynah Litaiff Isper Abrahim Carpinteiro. A lei de acesso à informação e a divulgação nominal da remuneração dos servidores públicos. Da transmutação do interesse 
público' em 'curiosidade coletiva'. Jus Navigandi, Teresina, ano 17, n. 3402, 24 out. 2012, Disponível em: <http://jus.com.br/artigos/22867>. Acesso em 08 ago. 2013.

PERLINGIERI, Pietro. O Direito Civil na Legalidade Constitucional. Rio de Janeiro: Renovar, 2008

TEPEDINO, Gustavo; BARBOZA, Heloísa H; MORAES, Maria Celina Bodin de. In: Código Civil interpretado conforme a Constituição da República. Vol. 1. Rio de Janeiro: Renovar, 2004

Artigo recebido em 09 de julho de 2013. Artigo aprovado para publicação em 16 de outubro de 2013.

DOI: $10.11117 / 1982-4564.06 .20$ 